\title{
如何有效节约国有资金，缓解国有资金压力 --立足工程合约造价分析
}

丁建华

南京软件园经济发展有限公司，江苏南京 213000

[摘要]目前建设领域企业普遍资产负债率增大, 这和大力发展建设财政吃紧、工程垫资、人工材料成本上涨、地价上涨、贷 款收紧等因素都有关系。就连资信良好的国有企业也难逃这一现实，大力发展建设带来了巨大的资金压力，没有大而多的收 入来源，融资方式单一，有限的财政资金支持不足以跟上发展步伐，国有企业也面临着资金链断裂的问题。

[关键词]项目决策; 目标成本; 限额设计；签证变更；招投标

DOI：10.33142/aem.v1i1.544 中图分类号：D632.1 文献标识码：A

\section{How to Save State-owned Funds Effectively and Relieve the Pressure of State-owned Funds--based on the Cost Analysis of Project Contract}

\author{
DING Jianhua
}

Nanjing Software Park Economic Development Co., Ltd., Jiangsu Nanjing, 213000 China

\begin{abstract}
At present, the asset-liability ratio of enterprises in the field of construction is increasing, which is related to the tight construction finance, the increase of the cost of artificial materials, the rise of land price, the tightening of loans and so on. Even the state-owned enterprises with good credit can not escape this reality. The vigorous development and construction has brought great capital pressure, there are no large and many sources of income, the financing mode is single, the limited financial support is not enough to keep up with the pace of development, and the state-owned enterprises are also facing the problem of broken capital chain.
\end{abstract}

Keywords: Project decision; Target cost; Quota design; Visa change; Bidding

引言

一个企业的良好运转, 涉及到各相关部门的通力合作, 如何有效节约国有资金, 缓解国有资金压力, 也是要从各 相关部门角度去思考的。以下就站在工程合约造价的角度, 发表一些简要的想法。

\section{1 项目决策阶段}

项目立项是项目决策阶段的核心。为了项目立项, 要完成可行性研究和项目建议书, 在可研报告和项目建议书内 要初步构想要做哪些东西并进行评价分析, 虽然立项阶段并没有好的准确的方法可以确认立项金额, 但是可以通过已 完类似项目进行指标分析, 按单方造价、生产能力估算立项金额。立项是项目的最高投资限额，国有企业普遍认为立 项越大越好，能保证整个项目正常开展，但是过大的立项，会导致盲目自信、铺张浪费的心理。

\section{2 项目实施阶段}

\section{1 设计前准备阶段}

本阶段需要做好项目策划、形成目标成本, 包括标段划分、施工界面划分、招标范围、功能分区、项目定位、开 发节点安排、目标成本制定等, 即预算投资额内明确要做什么做成什么样, 什么时候开工、建成等。该阶段的目标成 本应作为后续设计、施工的经济方面的基础。

\section{2 设计阶段（方案设计、技术设计、施工图设计）}

设计阶段的三阶段设计, 前一阶段是后一阶段的控制基础, 前期形成的目标成本更是设计阶段的控制基础。设计 概算为建设项目投资的最高限额，在设计阶段已经形成了项目 70-80\%的投资额，所以进行设计优化会对节约成本起到 立笔见影的效果。国有企业并不重视设计优化工作, 项目往往是着急上马, 留给设计院、建设单位设计部门的时间很 紧张, 如果建设单位对设计院限额设计交底不到位, 设计院往往是很保守设计, 不考虑经济性, 后期图审, 图审机构 也只是核实有没有违反强条标准, 对经济性指标也不在核查范围内, 所以国有企业项目大多是多花了很多钱, 但是并 没有实在提升项目的品质, 很多保守设计是不直观易见的东西。房地产企业都有设计优化单位, 优化单位按优化节约 投资额收取效益费用, 效益费用相对于工程建安费用很低, 但是起到的作用是 20-30\%的成本节约, 而且设计优化不光 
是节约成本, 也能发现不合理工艺, 会对工期、质量、安全、过程施工便利性带来很大麻烦的坚决要进行优化。

\section{3 施工阶段}

施工阶段的成本控制很有限, 无非就是签证、变更、索赔的管理, 但这些管理都是对既定事实的事项的管理。严 格控制设计变更增项, 签证变更索赔费用的严格审查, 复核事项能否给予增加费用。已经确定的图审图纸、招标清单, 一般国有企业不会做设计减项或降低标准, 也涉及到中标人项目利益分配的问题减项会艰难, 其中降低标准还存在是 否符合强条的问题, 所以施工过程中设计减项通常不太现实。加强进场材料验收, 确保按甲方要求的品牌档次进场。

\section{4 竣工结算阶段}

竣工验收阶段建议合约造价部相关成本负责人参与, 整体验收, 了解项目是否按图施工, 有无甩项漏项工作。结 算资料报送, 有造价复核能力的成本负责人应进行初次审核, 审查资料的完整性, 找出结算报价中清单子目的重大增 项及工程量的激增情况，重点分析，尤其注意压着合同价和超过合同价 10\%情况，一般此种情况是有一定虚报成分的。 最重要的就是在结算审核初稿确定阶段, 建设单位成本负责人对初审结果的审核, 发现问题, 存在争议的, 在公平公 正基础上，尽可能向着有利于建设单位利益方向去解释。项目竣工结算结束后，应注重成本复盘分析，找出重大签证、 变更事项、清单错漏项, 总结标段划分、界面划分混乱的不利影响, 统计各项经济指标、技术指标, 对比以往自建项 目及大企业成本数据找出差距，形成管理经验清单，后续项目学以致用，一步步完善公司成本管控流程。

\section{5 招标阶段}

招标工作贯穿整个项目实施阶段的始终，其重要性不言而喻。以下分几点说明:

(1)招标清单及招标控制价。清单控制价编制是根据设计图纸进行的, 形成的价格是对设计内容在造价的真实反映, 通过经济指标分析和技术指标分析, 可以发现设计图纸过于保守, 却忽视了经济性, 该指标也可以考核设计单位限额 设计的参考依据。清单控制价编制都有相关的编制方法约束, 成果也有审计局和招标办进行审核。每个造价师对于施 工方案、施工难以程度、对现场环境的了解程度及相关审计经验都不相同, 虽然定额是死的, 但是在每个造价师手上 使用的方式不完全相同, 所以说产生的造价也是不固定的。在这其中建设单位成本负责人就需要将可能引起各位造价 师理解偏差的因素找出来, 协调统一编制思想。比如渣土外运运距建设单位需要考察下土场, 测算大致运距告知造价 师; 现场原来是就厂房, 地下一定会有基础要拆除; 暂列金额的取值是多少; 省市级文明工地是否创建等。统一思想 后, 还要复查清单漏项, 价格明显错误, 工程量明显偏离, 清单特征描述不严谨等情况, 减少签证、调价等导致的造 价上涨。清单编制说明作为招标清单的组成部分, 对编制思路进行说明, 尤其重要的是对风险因素的考虑形成的说明, 这是减少过程中签证变更索赔很有力的补充，不从其法律效力上说，甚至可以认为清单编制说明是对合同条款的补充。 站在公平公正角度, 清单编制说明应避免霸王条款、无限制风险的描述, 让承包人承担超常规的风险, 同样对等的应 该在清单控制价内考虑相应风险费用, 即不能光承担风险不给费用, 这也是减少扯皮的一个方面。招标时间也对清单 控制价有影响, 年底招标, 材料价涨幅高, 导致控制价水平高, 年中招标, 材料价平稳较整年内低, 控制价水平较整 年内低, 虽然现在苏建价 [2008]67 号文由调价要求，但是考虑两种情况：年底的高价一般很少有其他月份能超过甚至 降低, 基本比较稳定, 至少 $5 \%$ 的材料价差收益是由施工方赚取; 年中的低价, 可能大多数的月份材料都会有涨幅, 这 是施工方根据政策应得的，但施工方必须承担至少 $5 \%$ 的价差损失。所以用机会成本的角度去看这件事，年中招标是对 建设单位资金有一定的节约。

(2)材料品牌、参数的约定。人工机械价格基本都有信息价参考, 虽然材料大多数也是有信息价参考的, 但是一旦 涉及到品牌、特定的参数, 信息价就仅是参考意义, 在编制清单控制价时需要进行市场询价计入, 如果不按品牌询价、 不负责任的按照信息价计入, 会导致按照建设单位品牌要求没有市场能买到, 施工过程中施工方一定会设法变更调整 价格。所以品牌约定尽可能采用较为常用的品牌, 政府采购法中也约定优先采用国产品牌, 这对材料价格的控制还是 很有作用的。还有要加强 “三选一” 品牌档次的审核, 这里面有两层含义: 建设单位推荐品牌需要和清单控制价材料 品牌计入水平相近; 三个品牌之间的档次要相近, 不然中标后施工方肯定选用最低档次的品牌无法满足建设单位实际 要求，也会面临被投标人投诉的风险。施工过程中，材料进场也要加强对品牌及参数的验收，确保建设单位花了钱买 到自己要的东西。

(3)招标文件。招标文件限价方面是依赖于招标控制价，其招标文件有个很重要的方面就是评标办法，选出合适的 中标人, 所有条件都是公平公正公开的, 采用合理低价法、综合评分法（五种方式）会对中标价格的大小产生影响, 合理低价法的中标价一般会比综合评分法低，但这并不绝对，中标价的产生是由各投标人采用各自的投标策略获取中 
标资格, 对项目利润高低预期不一致会影响投标价格, 当然是否采用合理低价法、综合评标法并不是建设单位随心所 欲选择的, 招投标导则会对如何选择评标办法有一定的指导性。在投标过程中, 评标委员会及建设单位主要着重核查 投标有无围标串标情况, 围标串标一般是几家投标人联合串标围标抬高中标价, 这就对节省国有资金很不利了, 所以 这种情况要坚决杜绝。

合同条款也是招标文件极为重要的部分。承包人应承担的职责及违约条款大多是站位工程现场管理角度对承包人 质量安全进度的管理措施, 相关的经济措施主要出现在合同款支付、结算方式、调价原则、风险约定范围。资金的时 间价值及建设单位投资者的角色，决定了建设单位在项目建设前期要尽可能的减少资金投入，并且资金支付节点越往 后越好, 目前《中华人民共和国国务院令》 712 号令约定工程项目不得由建设单位垫资施工, 虽然 712 号令这么要求, 但在工程建设领域行情低迷、建设单位资金压力大的情况下, 只有有实力的承包人才能承担工程。实力强的承包人资 金雄厚，能帮助建设单位提前抢房产预售节点，对于建设单位缓解前期资金压力有很大的作用。所以在设置合同价款 支付条款时, 在合理情况下尽可能降低前期价款支付比例, 在合理情况下采用承兑汇票解决付款问题。履约担保的设 置保护建设单位利益，但是合同法约定承包人提供履约担保同时，建设单位应提供支付担保，支付担保对于建设单位 又是一笔资金压力, 除了支付担保外, 开工 7 天前建设单位要支付 $10 \%$ 预付款，即 $20 \%$ 资金费用已投入，所以建设单位 应尽可能不提供支付担保, 是否需要承包人提供履约担保则视建设单位要求。

(4)工期要求。工期定额不是多有的情况都能含括, 政策影响、场地限制、特殊工艺等因素工期定额考虑不到, 需 要根据实际情况调整, 目前又出了装配式结构, 工期定额更没有考虑到, 不合理的工期设置也对建设单位资金使用的 松紧决策也有影响。建设单位想要赶工期, 就可能产生赶工措施费。

(5)标段划分。实行总承包, 目前有两种: 施工总承包和设计施工采购一体化总承包 (EPC), EPC 的弊端应该都有所 耳闻了, 施工总承包其实也不尽如人意。施工总承包必须确保在招标之前所有专业设计图纸完善, 编制招标清单后招 标, 这之间的时间流程还是很长的, 而且并不能面面俱到。那为何不采用分标段平行发包, 比如装修专业、幕墙专业、 室外景观绿化、室外道路雨污水等这些都可以单独深化设计后招标, 不需要只一次招标把所有问题解决, 实践证明, 一次性大总包并不能一次到位, 往往含糊设计的专业含糊放在大总包内一起招, 以后等设计深化或设计变更, 这是没 必要的。在专项工程施工前, 有大量的时间去进行专项设计深化、方案调整, 而且并不会耽误整体项目工期, 深化设 计后的清单也不容易发生大量的签证变更，也就是磨刀不误砍柴工的意思。

\section{3 结束语}

综上所述，项目全寿命周期内的方方面面都是会影响到投资成本的。在全社会固投指标的任务要求下，国企单位 确实很少注重节约成本，还是应该抓大放小，顾全全局，尽可能的节省资金做相对更多的事情，这就是节约。没必要 把太多精力去对抗水电燃气通信等垄断行业, 没必要把太多精力用于压缩勘察、设计、代理、咨询等服务行业的费用, 就是房地产企业也无法与垄断行业抗衡，延误一天交付就有一天的损失，应该把更多的精力放在设计优化、合同管理、 工程管理上, 工程管理包含了质量安全进度环保成本的管理, 环环相扣。人力成本是很低的, 一个人力成本一年 20 万, 多招 10 个人才 200 万的投入, 折算成工程费, 这也就是 8 万方的楼地面水泥砂浆找平的费用, 所以对于一个大项目来 说人力成本是微乎其微的, 更可以招聘一些经验丰富的工程行业人员, 提出的专业建议对于节约国有资金是比较轻松 的。

节约国有资金不是一朝一夕能做到的, 不是一个部门能做到的, 需要各部门通力合作, 花最经济的钱为公司做更 多的建设。

[参考文献]

[1]陆刚毅.关于 EPC 设计施工总承包项目管理的认识与思考 [J]. 住宅与房地产, 2018(13): 158 .

[2] 姜东芒. 关于对 EPC 设计施工总承包项目管理的认识与思考 [J]. 城市建设理论研究 (电子版), 2017 (15): 50-51.

[3] 赵卓. 对 EPC 设计施工总承包项目管理的认识与思考 [J].中国高新技术企业,2012 (16) : 142-145.

[4] 姚洁. EPC 设计施工总承包项目管理的认识与思考 [J]. 给水排水, 2012, 48 (04) : 102-104.

作者简介: 丁建华（1992-)，男，本科，工程项目管理专业，中级工程师。 